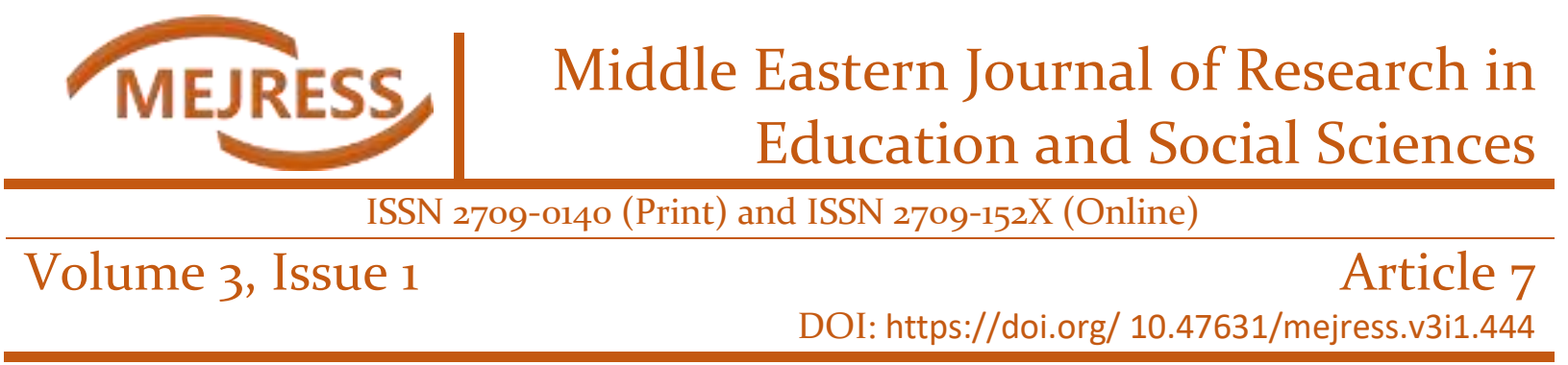

\title{
PARENTING STYLES AND SELF-ESTEEM: A STUDY OF LEBANESE ADOLESCENTS
}

\author{
Wassim Abou Yassin (D) Shakiba Daoud Nawal Farhat \\ School of Education, Lebanese International University, Lebanon \\ School of Education, Lebanese International University, Lebanon \\ School of Epidemiology and Public Health, University of Ottawa, Canada
}

\begin{abstract}
ARTICLE INFO
Received: 13 January 2022

Revised: 28 February 2022

Accepted: 02 February 2022

Keywords:

Parenting Styles, Self-Esteem,

Authoritative, Authoritarian,

Permissive.

Corresponding Author:

Shakiba Daoud

Email: shakiba.daoud@liu.edu.lb

Copyright (C) 2022 by Author(s)

This work is licensed under the Creative Commons Attribution International License (CC BY 4.0). http://creativecommons.org/licenses/ by/4.0/

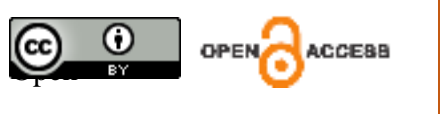

ABSTRACT

Purpose: This study aimed at identifying the prevailing parenting styles in the Bekaa region- (Lebanon) from adolescents' perspective. In addition, it aimed at detecting the adolescents' self-esteem levels, and the relationships between parenting styles and adolescents' self-esteem.

Approach/Methodology/Design: A purposeful sample of 728 students completed the study questionnaire. The questionnaire was adapted from previous studies and its validity and reliability were established. The study followed the descriptive analytical approach for the purpose of data collection and data analysis.

Findings: The results showed that the prevailing parenting style as perceived by adolescents in Bekaa is the authoritative style (88\%). Another finding was that $78.3 \%$ of the adolescents have normal levels of self-esteem. Moreover, Pearson's $r$ showed a moderate, positive and significant correlation between self-esteem and authoritative parenting style and a weak, negative correlation between selfesteem and both authoritarian and permissive parenting styles. Linear regression analysis indicated that the three parenting styles (authoritarian, authoritative and permissive) and father's educational level are the predictors of self-esteem.

Originality/value: The value of this study lies in serving the community by highlighting some points that play an important role in shaping and forming the personality of our children who, in turn, will be active members of our society.
\end{abstract}

\section{INTRODUCTION}

Parents play an important role in the transition of their children from one stage of life to another: from childhood to adolescence and from adolescence to adulthood. Parenting styles are considered important determinants in many aspects of children's development, particularly in the early years of a child's life which are believed to draw and shape a child's future. Developmental psychologists have been working on gaining a better understanding of the relationship between parenting styles and a child's behavior (Murphy, 2014). A landmark study that examines types of parenting styles was conducted by Diana Baumrind in 1960. It identified three styles: 1) authoritative style characterized as high in responsiveness and demandingness, 2) permissive characterized as high in responsiveness but low in demandingness, and 3) authoritarian characterized as low in responsiveness but high in demandingness. These three, were considered to encompass the different styles worldwide (Baumrind, 1978). Two decades later, Maccoby \& Martin (1983) added another parenting style which is the neglectful style. 
The aims of this study were to survey the parenting styles adopted by the parents in Lebanon from adolescents' perspective; to analyze the levels of adolescents' self-esteem; to find out the correlation between each parenting style and adolescents' self-esteem, the relationship between adolescents' self-esteem and gender, the relationship between gender and parenting styles and to assess whether there is a difference in adolescents' self-esteem in private and public schools. Specifically, the study investigated the following questions as they relate to parents in Bekaa, Lebanon:

1. What are the parenting styles that prevail from adolescents' perspective?

2. What are the levels of self-esteem among adolescents?

3. Is there a relationship between each parenting style and adolescents' self-esteem?

4. Is there a difference between males' and females' perspectives of their parenting styles?

5. Is there a relationship in the self-esteem and gender differences?

6. Is there a difference in the self-esteem levels of adolescents' in private and public schools?

\section{Research Hypotheses}

1. There is no significant correlation between parenting styles and adolescents' selfesteem levels.

2. There is no significant association between gender and parenting styles.

3. There is no significant difference in adolescents' self-esteem levels in public and private schools.

4. There is no significant difference between males' and females' perspectives of their parenting styles.

\section{LITERATURE REVIEW}

\section{Parenting Styles}

Darling and Steinberg (1993) defined parenting styles as a group of attitudes towards the child that are communicated to him and that are taken together to create an emotional climate in which parents' behaviors are expressed. Parenting is a complex activity that includes many behaviors which influence a child's personality (Darling, 1999). According to Maccoby and Martin (1983) there are two main dimensions underlying parental behavior: parental responsiveness and parental demandingness. Parental responsiveness can be referred to as parental warmth or supportiveness and the extent to which parents foster individuality, selfregulation, and self-assertion and caring to children's needs and demands. Parental demandingness can be referred to as behavioral control and to the pressure parents exert on children to become integrated in the family as a unit. In addition, it refers to their maturity demands, supervision, disciplinary efforts and willingness to confront the child who disobeys their orders (Maccoby \& Martin, 1983). The different parenting styles differ in the level of parental responsiveness and demandingness (Baumrind, 1971).

Many research studies relied on Diana Buamrind's explanation when explaining the concept of parenting styles. The construct of parenting styles is used to describe normal variation in parents' efforts to control their children and socialize with them (Baumrind, 1991). Baumrind's three parenting styles of authoritarian, permissive, and authoritative are often used in studies that investigate the relationship between parenting styles parenting styles and different outcomes in children like motivation, self-esteem, academic achievement, cognitive 
ability, aggression, peer acceptance, social acceptance, and academic self-efficacy (Ginsburg \& Bronstein, 1993). Baumrind (1973) describes each of the styles as follows:

1. Authoritarian Parenting Style: is characterized by low responsiveness and high demandingness. These parents are often emotionally detached but very controlling. They use force and power to control without questioning, discussion, or explanation. They exert a high degree of control and value a clear and structured environment and obedience to rules.

2. Permissive Parenting Style: Permissive parents display high levels of warmth and low levels of control. They are responsive to their children's emotional needs but are not controlling or demanding. As a means of punishment, they use love withdrawal and ridicule. Although permissive parents are child-centered, they are prone to anger outbursts when they reach their full capacity of tolerance.

3. Authoritative Parenting Style: When interacting with their children, authoritative parents show high levels of warmth and control. This style of parenting provides a balance between authoritarian and permissive parenting. Authoritative parents use reasoning, discussion, and explanation in a consistent manner. To discipline their children, these parents use positive reinforcement and discussion of reasons and consequences. They also communicate with their children clearly and encourage their independence.

\section{Predominant Parenting Styles in Arab Countries}

Culture plays a role in structuring parenting styles as it provides guidelines to parenting. Thus, different countries and different ethnic groups have their own predominant parenting styles (Dwairy, Farah, Fayad \& Khan, 2006). The parenting styles in traditional countries such as Yemen and Saudi Arabia were found to be more authoritarian than those in other countries, such as Lebanon and Jordan (Dwairy, Farah, Fayad \& Khan, 2006). A study conducted by Abou Yassin, Daoud, Sabri \& Mortada (2018) regarding the prevailing parenting styles from parents' perspective in Bekaa, Lebanon showed that the authoritative parenting style is dominant. Similar findings in Lebanon were reported by Dwairy (2006).

\section{Predominant Parenting Styles in Regions of the World}

Several studies have examined parental practices in different regions and cultures. According to Damon \& Lerner (2006), the majority of parents from the West, like Australia, United States, and European Countries, mostly adopt authoritative parenting styles. A study conducted by Mekonnen (2017) in Ethiopia, regarding the parenting styles used in Bahir town, indicated that the authoritative parenting was the most prevalent, followed by authoritarian and permissive styles, the neglectful styles were the least common. Among Vietnamese adolescents, a study by Nguyen (2008) showed that adolescents perceived authoritarian parenting style as the predominant style in Vietnam. Amongst Latino families, researchers have described parenting styles as permissive (Julian, Mckenry \& Mckelvey, 1994) or as authoritarian (Darling \& Steinberg, 1993; Hammer \& Turner, 1990). Other researches, such as Vega found that parent and child interactions were nurturing and mostly characterized by warmth (Vega, 1990).

\section{Self-Esteem}

William Rosenberg, one of the pioneers in this domain, mentions that self-esteem refers to the individual's overall positive evaluation of the self. Therefore, an individual with high 
self-esteem is characterized by respecting himself and considering himself worthy (Rosenberg, 1965).

William James believed that the individual's self-esteem lies in the area between one's ideal self and one's perceived self. Humans are able to recognize themselves as objects and form feelings and attitudes towards themselves (James, 1980). Abraham Maslow identified selfesteem as one of the basic human motivators. In his concept of the hierarchy of needs, selfesteem comes near the top after physical needs, and security and safety needs. Following these basic needs, there are the psychological needs of esteem and self-actualization, where one can finally fulfill his full potential (Maslow, 1987).

The formation of self-esteem is a long process. It includes downfall periods especially during transitions from one stage to another or from one status to another (Robins, Orth \& Trzesniewski, 2010). According to Ying, Tsai \& Lee (2001), self-esteem declines during adolescence and it increases during young adulthood. According to Rosenberg Self-Esteem Scale (1965), low self-esteem ranges between 0-15, normal self-esteem between 15-25 and high self-esteem above 25 .

\section{Parenting Styles and Self-Esteem}

The relationship between parenting styles and self-esteem has received much attention. Some researchers found that authoritative parenting style positively correlated with high levels of self-esteem while other researchers found that permissive parenting style positively correlated with high levels of self-esteem. Further, others suggest that the authoritarian parenting style negatively correlated with high levels of self-esteem.

Regarding the relationship between authoritative parenting style and self-esteem, a cross cultural research has reported that children, in both Asia and western countries, whose parents use authoritarian parenting style, tend to show higher levels of depression and lower levels of self-esteem (Herz \& Gullone, 1999). Conversely, children whose parents use authoritative parenting style tend to report higher levels of self-esteem, a well-developed sense of self, and confidence (Gunnoe, Herterington \& Reiss, 1999). Similarly, studying Japanese college students, Yamawaki, Nelson \& Omoni (2010) found that warm and caring parenting which is a characteristic of authoritative parenting may be a vital factor of the individuals' psychological well-being. However, among African and Asian-American Adolescents, no evidence has been found regarding the positive influence of authoritative parenting on self-esteem (Brown, Steinberg \& Dornbusch, 1992). Our study showed that children whose parents use authoritative parenting styles have high levels of self-esteem while children whose parents use authoritarian and permissive parenting styles have low levels of self-esteem.

Likewise, a study conducted in the United Kingdom showed a strong association between the authoritative parenting style and high levels of self-esteem (Chan \& Koo, 2010). Moreover, Weiten, Dunn \& Hammer (2014) showed that authoritative parenting is associated with the highest self-esteem scores while authoritarian, permissive and neglectful parenting ranked second, third and fourth respectively. Furthermore, the study of Tkacova revealed that there is a positive correlation between authoritative and permissive parenting styles and self-esteem and a negative correlation between authoritarian parenting styles and self-esteem (Tkacova, 2017). Additionally, a cross-sectional study found small to moderate positive associations of authoritative parenting with self-esteem while authoritarian parenting related to lower selfesteem and a very small positive association of permissive parenting with self-esteem 
(Pinquart \& Gerke , 2019). Thus, authoritative parenting is viewed as the best parenting style in western countries (Ang \& Goh, 2006).

The Canadian Council on Learning (2007) showed that authoritative parenting is linked to greater social competence, and children of this parenting style have better self-esteem. Additionally, according to Bronstein \& Zoltinik (2008) authoritative parental behaviors play an important role in influencing self-esteem of children.

On the other hand, contradictory results were reported by a study conducted by Martinez and Gracia (2008). This study investigated the relationship between permissive parenting style and self-esteem. Results suggest that children of permissive parents had the highest levels of self-esteem while those of authoritarian parents had the lowest levels of self-esteem. In a subsequent study, Gracia and Gracia (2009) found that children of permissive and authoritative parents had the highest levels of self-esteem. In another study conducted by Heaven \& Ciarrochi (2008) children from permissive families were also found to be autonomous in making their own decisions and expressing their individuality. Similarly, the study of Lee revealed that children from permissive families who have experienced psychological autonomy tend to have higher self-esteem than children from authoritative and authoritarian (Lee, 2011).

To examine the relationship between the authoritarian parenting style and self-esteem, the study of Bronstein \& Bronstein (2007) revealed that authoritarian parenting is linked to positive social outcomes among Asian families. In a study conducted in Palestine, Dwairy (2004) found that unlike the results in the West, authoritarian parenting was not associated with low levels of self-concept and self-esteem. According to Chao (2001), the authoritarian parenting style is more beneficial for feelings of self-esteem in some cultures that perceived authoritarian characteristics as caring and loving.

\section{Self-Esteem and Gender}

Gender as a social construct is directly connected with differences in socialization practices such as the influence of parents, peers and teachers. Society, culture and family shape the individuals' sex stereotypes. The environment provides strong cues for the individuals' behavior (Rifai, 2008). Consequently, gender differences in certain areas such as self-esteem are consistent with gender stereotypes which are relatively stable from preadolescents to adulthood (March, 1989).

Most of the studies on gender and self-esteem found that adolescent females score lower on self-esteem than adolescent males (Cairns, Mcwhirter, Duffy \& Barly, 1990). Rosenberg and Simmons (1973) found that a greater proportion of girls reported lower self-esteem relative to boys during middle and late adolescence. Another study conducted by Chubb, Fertman \& Ross (1997) in the USA regarding the gender differences in high school revealed that males' self-esteem was significantly higher than that of females. Similar results were found in a study conducted in Toronto, Canada revealed that females were found to have significantly lower self-esteem than males (Raymore, Godbey \& Crawford, 1994).

On the contrary, Coopersmith (1976) found no difference in the means of self-esteem between males and females in the $5^{\text {th }}$ and $6^{\text {th }}$ grades. Similarly, according to Ferguson \& Fraser (1998) there is no significant difference between males' and females' self-esteem among students in grade 6. Likewise, Turkish adolescents' females had self-esteem scores similar to those of adolescent males (Sahin, Barut \& Ersanli, 2013). Moreover, a study 
conducted in North Lebanon shows that there is no significant difference in self-esteem between male and female adolescents (Rifai, 2008).

\section{Parenting Styles and Gender}

The relationship between parenting styles and gender was investigated in many studies whcich reported different results. A multi-country study conducted in Sweden, Italy and Greece, showed that the authoritative parenting style, according to both boys' and girls' perceptions, is the most adopted style (Olivari, Wahn, Kassotaki \& Antonopoulou, 2015). According to Vietnamese female and male adolescents, the dominant parenting style in Vietnam is the authoritarian parenting style (Nguyen, 2008). In Nigeria, both male and female adolescents perceive their parents as authoritative and authoritarian (Osenweugwor, 2014). In contrast, a study in Pakistan revealed that boys and girls had different perceptions of their parenting styles; girls perceived their fathers as more permissive and authoritative compared with boys, and boys perceived their mothers as more authoritative (Kuasar \& Shafique, 2008).

\section{Self-Esteem and School Type}

Few studies have examined the relationship between self-esteem and school type. The study of Ermie and Chikwerk (2015) revealed that private school students in Nigeria demonstrated high levels of self-esteem, while public school students have low levels of self-esteem.

\section{Self-Esteem and Father's Education}

A study that was conducted in Toronto, Canada reported that parents' education plays an important role in developing adolescents' self-esteem (Raymore, Godbey \& Crawford, 1994). Moreover, the studies of Rosenberg \& Pearlin (1978) and Bachman, O'Malley, Freedman, Trzesniewki \& Donnellan (2011) suggest that that there is a positive association between parents' education and adolescents' self-esteem.

\section{Adolescence}

Adolescence is a Latin word which means "to grow into adulthood". Adolescence is a distinct phase of developmental life cycle in humans (Feldman \& Elliot, 1993). It is a period of moving from the immaturity of childhood to the maturity of adulthood. This journey requires a set of transitions that can be biological, cognitive, social and emotional (Steinberg, 2002). Stanley Hall, the founder of adolescent science, described adolescence as a process of physical and psychosocial "rebirth" (Arnett, 2002).

The adolescence stage ranges between ages 10-19 years, but many incorporate the span of 926 years. It can be categorized into three stages: early adolescence (12 to 14 years), middle adolescence (15 to 16 years), and late adolescence (17 to 19 years) (APA, 2002).

Many reasons inspired the authors to conduct this research; lack of studies in the domain of parenting styles and self-esteem in Lebanon; the need of raising awareness in our community about the role played by the family in the development of its members and the necessity to communicate and interact with each other, and finally to raise awareness in schools about the concept of self-esteem which corresponds with many aspects of children's educational life like academic performance, aggression and peer acceptance. 


\section{Participants' Characteristics}

The sample selected in this study is a purposeful sample. A total of 1027 questionnaires were administered to students in grades ten and eleven from 14 public and private schools in Bekaa region. The completed questionnaires were collected and used to answer our research questions.

\section{Research Instrument}

The instrument used in this study is a questionnaire developed by the researchers, based on previous literature, to assess parental styles from the adolescents' point of view. The questionnaire items were based on different standardized questionnaires and scales: Rosenberg self-esteem scale (Rosenberg, 1965), a self-report instrument for evaluating individual self-esteem, Parental Authority Questionnaire PAQ (Buri, 1991) and its updated version: Parenting Styles \& Dimensions Questionnaire PSDQ (Robinson et al., 2001). The study questionnaire consisted of 48 items: 6 items related to personal data 32 items were designed to reflect the three parenting styles previously described, and the remaining 10 items were used to evaluate adolescents' self-esteem. The respondents were directed to respond to the 32 items on a 6-point Likert scale (ranging from $1=$ never to $6=$ always) and for the 10 items on a 4-point Likert scale (ranging from $1=$ strongly disagree to $4=$ strongly agree).

The questionnaire was reviewed by a group of six experts in the field of education who provided their recommendations and suggested modifications related to clarity of items, cultural aspects, or language use, to ensure validity of the tool among Lebanese people. Afterwards test-retest reliability was performed to check the reliability of the questionnaire. It was piloted among a group of 10 students in grades ten and eleven who were not part of the study sample.

\section{Statistical Analysis}

Data from all completed questionnaires was coded and entered into Excel, then imported to SPSS for analysis. Questions that were unanswered were entered as 'missing'. Categorical variables were summarized by noting the frequency and percentages of responses for each category using tables and charts. Means and standard deviations were calculated for continuous variables. The Pearson correlation was calculated for the mean score of each parenting style (authoritarian "AN", authoritative "AV" and permissive "PV") with the selfesteem score. A p-value of less than 0.05 was considered to indicate the presence of a statistically significant correlation between the two variables.

To assess whether there was a relationship between categorical variables of interest (parenting style and self-esteem; gender and self-esteem; gender and parenting styles) chisquared analyses were performed. A p-value of less than 0.05 was used to suggest the presence of a relationship, while a p-value of more than 0.05 suggested independence of the two variables (no relationship).

Linear regression analysis was used to determine predictors of the self-esteem score (dependent variable). Independent variables were parenting styles, age, gender, school type, father's education, mother's education, father's employment status and mother's employment status. 
Forward stepwise linear regression was used. In this method, the statistical software attempts to include all variables. In the final model that is output, only the significant variables are kept. The variables remaining in the model can be considered as predictors of the dependent variable. All statistical analyses were conducted using SPSS software.

\section{RESULTS AND DISCUSSION}

A total of 728 completed questionnaires were collected from students, with a response rate of $72 \%$. Results show that the majority of the adolescents in the study perceive their parents as authoritative (88.2\%), while nearly equal percentages of the adolescents perceive their parents as permissive (6.0\%) and authoritarian (5.8\%) (Fig.1).

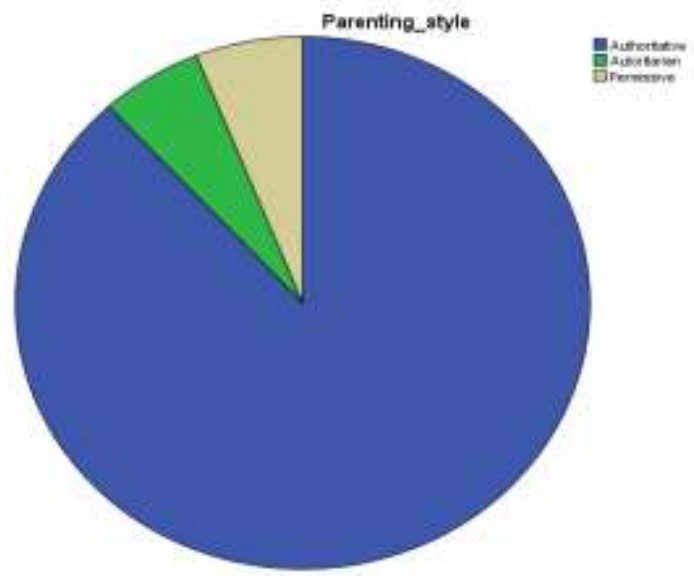

Figure 1. The distribution of parenting styles in the study sample

Based on Rosenberg Self Esteem Scale (SES), self-esteem scores range from 0-30. Scores between 15 and 25 are within normal range, scores below suggest low self-esteem while higher scores indicate high self-esteem (Fig.2).

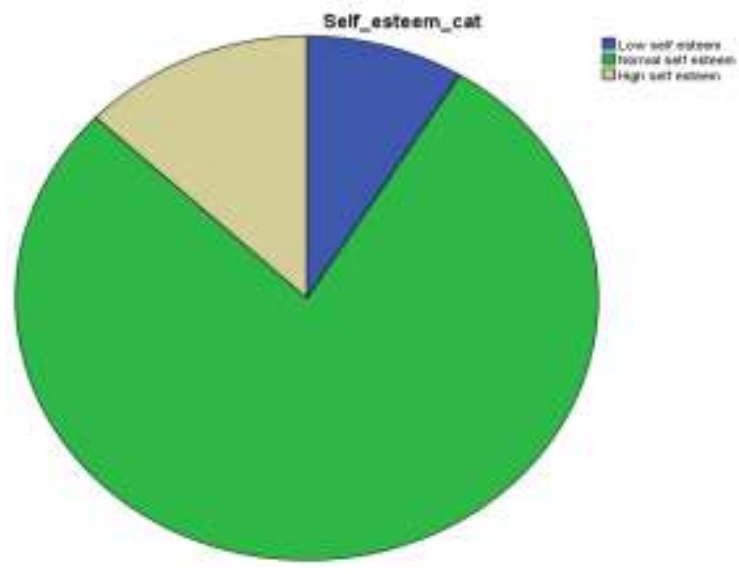

Figure 2. The distribution of levels of self-esteem in the study sample

The results revealed that the vast majority of the adolescents in the study have normal selfesteem (78\%), while $12.9 \%$ have high self-esteem and $8.8 \%$ have low self-esteem. The results suggest that there is a moderate positive correlation (Pearson correlation +0.35 ) between authoritative parenting style and self-esteem and a weak negative correlation 
between both permissive and authoritarian parenting style scores and self-esteem scores (Pearson correlation -0.13 and -0.27, respectively) (Table 1).

Table 1. Correlation between parenting styles and self- esteem

\begin{tabular}{lll}
\hline Variable & Pearson Correlation & P- value (significance) \\
\hline Self-esteem score & 0.348 & 0.00 \\
$\begin{array}{l}\text { Mean AV score } \\
\text { Self-esteem score }\end{array}$ & -.130 & 0.00 \\
$\begin{array}{l}\text { Mean PV score } \\
\text { Self-esteem score }\end{array}$ & -.271 & 0.00 \\
Mean AN score & & \\
\hline Source: Authors & &
\end{tabular}

Using chi-squared analysis to test whether students' gender is related to self-esteem levels in the sample, we found that the two variables are independent (p-value 0.47) suggesting a lack of a relationship (Table 2).

Table 2. Chi squared analysis between gender and self esteem

\begin{tabular}{cllll}
\hline \multirow{2}{*}{ Gender } & \multicolumn{2}{l}{ Self-esteem level } & & $\begin{array}{l}\text { Chi-squared p- } \\
\text { value }\end{array}$ \\
\cline { 2 - 5 } Females & Low & Normal & High & \\
Males & $10.9 \%$ & $79.8 \%$ & $12.3 \%$ & 0.467 \\
\hline
\end{tabular}

Source: Authors

The results of chi- squared indicate that there is no association between parenting style (AV, AN or PV) and gender (corresponding p-values were greater than 0.05 ). This suggests that in our study sample, students' gender was independent of their perspectives of the parenting style (Table 3).

Table 3. Chi squared analysis between parenting styles\& gender

\begin{tabular}{lllll}
\hline \multirow{2}{*}{ Gender } & \multicolumn{2}{l}{ Parenting Style } & & $\begin{array}{l}\text { Chi-squared p- } \\
\text { value }\end{array}$ \\
\cline { 2 - 5 } Females & AV & AN & PV & \\
Males & $57.3 \%$ & $50 \%$ & $63.6 \%$ & 0.441 \\
\hline
\end{tabular}

Source: Authors

Results of chi-squared analyses show that there is no association between school and selfesteem in our sample (p-value 0.86). This means that self-esteem level in our sample was independent of whether the students attended public or private schools (Table 4).

Table 4. Chi-squared analyses between self -esteem and school type

\begin{tabular}{lllll}
\hline \multirow{2}{*}{ Gender } & Self-esteem level & & \multicolumn{2}{c}{$\begin{array}{l}\text { Chi-squared p- } \\
\text { value }\end{array}$} \\
\cline { 2 - 5 } Public & Low & Normal & High & \\
Private & $8.7 \%$ & $78.8 \%$ & $12.5 \%$ & 0.861 \\
\hline SourC: & $9.1 \%$ & $77.0 \%$ & $13.9 \%$ & \\
\hline
\end{tabular}

Source: Authors

\section{Regression Analyses}

Linear regression analysis was performed in order to identify predictors of the self-esteem score among the study sample. The self-esteem score was the dependent variable. 
Independent variables in the model were: authoritative parenting style (mean score), authoritarian parenting style (mean score), permissive parenting style (mean score), school type, participant's age, mother's education level, father's education level, mother's employment status and father's employment status. Results of the regression analysis suggest that all three scores of parenting styles in addition to father's education were significant in predicting parenting style ( $\mathrm{p}$-value for the corresponding regression coefficient (beta) was less than 0.05) ( Table 5).

Table-5. Regression coefficients for the independent variables that were found significant in the linear regression model

\begin{tabular}{lcc}
\hline Independent variable & Regression Coefficient (beta) & p-value \\
\hline Mean- AV & 1.746 & 0.00 \\
Mean- AN & -.777 & 0.00 \\
Mean- PV & -.575 & .002 \\
Father's education & .424 & .007 \\
\hline
\end{tabular}

Source: Authors

Findings from the linear regression model indicate that the authoritative parenting style score (mean AV) is the strongest predictor of the student's self-esteem score. The corresponding regression coefficient was 1.75 , suggesting that when the authoritative parenting style score increased by one unit, the self-esteem score increased by 1.75 units if the other three variables in the model are kept constant. Using similar interpretation, when the authoritarian parenting style score or the permissive parenting style score increased by 1 unit, the selfesteem score of the student decreased by 0.78 and by 0.58 units, respectively. We also found that when the father's education decreased by one level (levels measured were $\mathrm{PhD}, \mathrm{MS}, \mathrm{BS}$, $\mathrm{BC}$, none), the self-esteem score of the student increased by 0.42 units.

\section{Discussion}

The first research question "What are the parenting styles that prevail in the Bekaa region in Lebanon from adolescents' perspective?" has no hypothesis since it is a descriptive question. The results reveal that the prevailing parenting style in the Bekaa region in Lebanon according to the sample is the authoritative with $88.2 \%$ followed by equal percentages for authoritarian and permissive parenting styles with $5.8 \%$ and $6 \%$, respectively. This result is consistent with the findings of the cross regional study of Dwairy (2006) and the study of Abou Yassin et al. (2018) which reveal that prevailing parenting style from parents' perspectives is the authoritative parenting style.

The second question "What are the levels of self-esteem during adolescence stage in Bekaa region in Lebanon?" has no hypothesis too since it is also a descriptive question. The results show that $87 \%$ of the adolescents in Bekaa region according to the sample have normal selfesteem, $12.9 \%$ have high self-esteem and $8.8 \%$ have low self-esteem. This result contradicts with the findings of the studies of Ying, Tsai \& Lee (2001) and Robins, Orth \& Trzesniewski (2010) which show that self-esteem declines during adolescence stage.

The hypothesis "There is no significant correlation between authoritative parenting style and self-esteem" was rejected because the results reveal that, according to the sample, there is a positive and moderate correlation between authoritative parenting style and adolescents' selfesteem in Bekaa. This suggests that as authoritative parenting style increases, the levels of self-esteem increase. Findings from the linear regression analyses suggest that parenting styles are a predictor of the students' self-esteem where the authoritative parenting style is the strongest predictor. Thus the results are consistent with the findings of Maccoby \& Martin 
(1983), Gunnoe, Hetherington \& Reiss (1999), Bronstein \& Zoltinik (2008), Chan \& Koo (2010), Weiten, Dunn \& Hammer (2014), and Osenweugwor (2014) which indicate that authoritative parents raise children with high self-esteem.

The hypothesis "There is no significant correlation between authoritarian parenting style and adolescents' self-esteem" was rejected since the results show a weak and negative correlation between authoritarian parenting style and self-esteem, which means as authoritarian parenting style increases, self-esteem levels decrease. This result is consistent with the studies of Herz \& Gullone (1999) and Ang \& Goh (2006) which report that children whose parents use authoritarian parenting style tend to show lower levels of self-esteem. However, our results are contrary to those reported by Chao (2001), Dwairy (2004), Rudy \& Grusec (2006), and Bronstein \& Bronstein (2007), which point out that authoritarian parenting style is linked positively with self-esteem.

The hypothesis "There is no significant correlation between permissive parenting style and adolescents' self-esteem" was rejected since the results reveal that there is a weak and negative correlation between permissive parenting style and self-esteem, which means as permissive parenting style increases, self-esteem levels decrease. This result contradicts with the findings of Martinez \& Gracia (2008) and Lee (2011) which indicate that adolescents from permissive homes have high levels of self-esteem. They also contradict with the study of Gracia \& Gracia (2009) that shows that children of permissive parents tend to have higher self-esteem than children from authoritative and authoritarian families.

The hypothesis "There is no relationship between gender and self-esteem" was accepted because the results show no association between gender and self-esteem. This is consistent with the findings of Coopersmith (1967), Rifai (2008) and Sahin, Barut \& Ersanli (2013)

The hypothesis "There is no significant difference between males' and females' perspectives of their parenting styles" was adopted since the results show no association between gender and parenting styles. This finding is consistent with those reported by Osenweugwor (2014) and Olivari, Wahn, Kassotaki \& Antonopoulou (2015), studies conducted in Sweden, Italy, Greece \& Nigeria, which revealed that the authoritative style, according to both boys' and girls' perceptions, is the most frequently adopted style. However, this study finding is contrary to the findings of Kuasar \& Shafique (2008) which show that girls perceived their fathers as more permissive and authoritative compared with boys and boys perceived their mothers as more authoritative. Our finding also contradicts Nguyen's results which show that according to Vietnamese female and male adolescents the dominant parenting style in Vietnam is the authoritarian parenting style (Nguyen, 2008).

The hypothesis "There is no significant difference between adolescents' self-esteem in public and private schools" was accepted since the results show that there is no association between school type and adolescents' self-esteem. However, this finding contradicts the results of Ermie \& Chikwerk (2015) that suggest that private school students demonstrated high selfesteem while public schools students had low self-esteem.

The findings from the regression analyses suggest that fathers' education is a predictor of the students' self-esteem; when father's education decreases by one level, the student's selfesteem score increases by 0.42 units. This result contradicts with the study of Rosenberg \& Pearlin (1978), Raymore, Godbey \& Crawford (1994) and Bachman, O'Malley, Freedman, Trzesniewski \& Donnellan (2011) which indicate that there is a positive association between parents' education and adolescent self-esteem. Our findings came contrary to what we expected since, according to Robinson et al. (2001), it is assumed that educated fathers may 
be more knowledgeable when dealing with their adolescents, communicating with them, motivating them to make decisions, and encouraging them to form positive attitudes toward themselves, which all play a crucial role in developing their self-esteem.

\section{CONCLUSION AND SUGGESTION}

This study aimed to serve the community by highlighting some points that play an important role in shaping and forming the personality of our children who in turn will be active members of our society. We conclude that the dominant parenting style, from the adolescents' point of view, in Bekaa, Lebanon is the authoritative style which is the most balanced among other parenting styles according to previous studies. Furthermore, the levels of self-esteem results are reassuring because our findings suggest that adolescents for the most part have normal levels of self-esteem.

\section{ACKNOWLEDGEMENTS}

We are grateful to all practitioners who have shared their time with us and for their valuable comments and insights regarding our research. We would also thank the participants, the students of grades ten and eleven for being an essential part in this research.

\section{CONFLICT OF INTEREST}

No potential conflict of interest was reported by the authors.

\section{FUNDING}

No funds received for conducting this study.

\section{REFERENCES}

Abou Yassin, W., Daoud, S., Sabri, N., \& Mourtada, A. (2018). Parenting styles and their correlation with the family's socioeconomic status from the point of view of parents. London: International Center for Educational \& Family Strategies (ICEFS) ISBN: 978-1-9160489-0-4.

Ang, R., \& Goh, D. (2006). Authoritarian parenting style in Asian societies: a cluster analytic investigation. Contemporary Family Therapy, 28(1), 131-153. https://doi.org/10.1007/s10591-006-9699-y

APA. (2002). Developing adolescence: a reference for proffessionals. Washington DC: American Psychological Society.

Arnett, J. (2002). The psychology of globalization. American Psychologist, 57(10), 774-783. https://doi.org/10.1037//0003-066X.57.10.774

Bachman, G., O'Malley, M., Freedman, P., Trzesniewski, H., \& Donnellan, M. (2011). Adolescent self-esteem : Differences by race/ethnicity, gender and age. Self and Identity, 445-473. https://doi.org/10.1080\%2F15298861003794538

Baumrind, D. (1971). Current patterns of parental authority. Developmental Psychology Monograph, 4, 1-103. https://doi.org/10.1037/h0030372

Baumrind, D. (1973). The development of instrumental competence through socialization. Minisota Symposia on Child Development, 3-46. https://doi.org/10.4236/jwarp.2014.66054

Baumrind, D. (1978). Parental discplinary patterns and social competence in children. Youth and Society, 763-776. https://doi.org/10.1177/0044118X7800900302 
Baumrind, D. (1991). The influence of styles on adolescent competence and substance use . The Journal of Early Adolescence, 59-95. https://doi.org/10.1177/0272431691111004

Bronstein, M., \& Zoltinik, D. (2008). Parenting styles \& their effects. Encyclopedia of Infant \& Early Childhood Development, 496-509. https://doi.org/10.1016/B978-012370877$\underline{9.00118-3}$

Branden, N. (1969). The Psychology of Self-Esteem . Bantman .

Bronstein, L., \& Bronstein, M. (2007). Parenting styles \& their effects . Encyclopedia of Early Childhood Development.

Buri, J. (1991). Parental Authority Questionnaire. Journal of Personality \& Social Assessment, 110-119. https://doi.org/10.1207/s15327752jpa5701_13

Burnett, W., Anderson, P., \& Paul, P. (1995). Gender roles \& self esteem.: a consideration of environmental factors. Journal of Counseling \& Development, 73(3), 323-326. https://doi.org/10.1002/j.1556-6676.1995.tb01757.x

Canadian Council on Learning. Parenting Styles, Behavior and Skills and their Impact on Young Children. (2007, December 13).

Cairns, E., Mcwhirter, L., Duffy , U., \& Barly , R. (1990). The stability of self concept in late adolescence: gender \& situational effects. Personality \& Individual Differences, 11(9), 937-944. https://doi.org/10.1016/0191-8869(90)90275-V

Chan, T., \& Koo, A. (2010). Parenting style \& youth outcomes in the United Kingdom. European Sociological Review, 27(3), 1-15. https://doi.org/10.1093/esr/jcq013

Chao, R. (2001). Extending research on the consequences of parenting styles for Chinese American and European Americans. Child Development, 72, 1832-1843. https://doi.org/10.1111/1467-8624.00381

Coopersmith, S. (1967). The Antecedents of Self Esteem. San Fransisco: Freeman.

Damon, W., \& Lerner, M. (2006). Handbook of Child Psychology (6th ed.). San Francisco: John Wiley and sons.

Darling, N., \& Steinberg, L. (1993). Parenting style as context: An interactive model. Psychological Bulletin, 1113, 487-496. https://doi.org/10.1037/0033-2909.113.3.487

Darling, N. (1999). Parenting Styles and its Correlates. Eric Digest.

Darling, N., Steinberg, L., Dornbusch , M., \& Lamborn , D. (1992). Impact of parent practices on adolescent achievement: authoritative parenting, school involvement, and encouragement to succeed. Child Development, 63(5), 266-281. https://doi.org/10.1111/j.1467-8624.1992.tb01694.x

Davies, T., \& Lindsay, L. (2004). Interpersonal conflict and adolescent adjustment: Why does gender moderate early adolescents vulnerability? . Journal of Family Psychology, 160-170. https://doi.org/10.1037/0893-3200.18.1.160

Dockter, M. (1991). A study of the relationship between junior high school students' knowledge and understanding in learning style theory and their self esteem. Dissertation Abstracts International, 1959-1960.

Dwairy, M., Farah, A., Fayad, M., \& Khan, K. (2006). Parenting styles in Arab societies: a first cross culture study. Parenting Journal of Cross Cultural Psychology, 37, 1-18. https://doi.org/10.1177/0022022106286922

Dwairy, M. (2004). Parenting Styles and Mental Health of Arab Gifted Adolescents. Gifted Child Quarterly, 48(4). https://doi.org/10.1177/001698620404800403

Dwairy, M. (2006). Parenting style, individuation and mental health of Egyptians . Journal of Adolescence, 29, 103-117. https://doi.org/10.1016/j.adolescence.2005.03.002

Ermie, M., \& Chikwerk, A. (2015). Self-esteem among private and public schools students in River State: implications for counselling. Kuwait Chapter of Arabian Journal of Business and Management Review. 
Feldman, S., \& Elliot, G. (1993). At the threshold: the developing adolescent. Harvard University Press.

Ferguson, P., \& Fraser, B. (1998). Student gender, school size and changing perceptions of sceince learning environment during the transition from primary to to secondary school. Research in Sceince Education, 387-397. https://doi.org/10.1007/BF02461506

Ginsburg, G., \& Bronstein, P. (1993). Family factors related to children's intrinsic / extrinsic motivational orientation and academic performance. Child Development, 64(5), 14611474. https://doi.org/10.1111/j.1467-8624.1993.tb02964.x

Gracia, F., \& Gracia, E. (2009). Is always authoritarian the optimum parenting style? Evidence from Spanish families. Adolescence, 101-131.

Gunnoe, M., Hetherington, M., \& Reiss, D. (1999). Parental religiosity, parenting styles \& adolescents' social responsibility. Journal of Early Adolescents, 19(2), 199-225. https://doi.org/10.1177/0272431699019002004

Hammer, T., \& Turner, P. (1990). Parenting in Contemporary Society. Allyn \& Bacon.

Heaven, P., \& Ciarrochi, J. (2008). Parental Styles, gender and the development of Hope \& Self-Esteem. European Juornal of Psychology, 22, 707-727. https://doi.org/10.1002/per.699

Herz, L., \& Gullone, E. (1999). The relationship between self- esteem \& parenting styles: A cross cultural comparison of Australian and Vietnamese Australian adolescents. Journal of Cross Cultural Psychology, 30(6), 742-761. https://doi.org/10.1177/0022022199030006005

James, W. (1980). Principles of Psychology. New York: Henry Holt.

Julian, T., Mckenry, P., \& Mckelvey, M. (1994). Cultural variations in parenting: perceptions of Caucasian, African-American, Hispanic, and Asian-American Parents. Family Relations: An Interdisciplinary Journal of Applied Family Studies, 43(1), 30-37. https://doi.org/10.2307/585139

Kuasar, R., \& Shafique, N. (2008). Gender differences in perceived parenting styles and socioemotional adjustment of adolescents . Pakistan Journal of Psychological Research, 93-105. https://link.gale.com/apps/doc/A259960708/AONE?u=anon dbdc9730\&sid=googleSchol ar\&xid=2b554d18

Lee, C. (2011). A study of relationship between parenting styles and self esteem: self esteem indicator- parenting styles.

Maccoby, E., \& Martin, J. (1983). Socialization in the Context of the Family: Parent- Child Interaction. New York: Wiley.

March, H. (1989). Age \& sex effects in multiple dimension of self concept preadolescence to early adulthood. Journal of Educational Psychology, 18(3), 417-430. https://doi.org/10.1037/0022-0663.81.3.417

Martinez, I., \& Gracia, J. (2008). Parenting styles and self esteem among Brazilian teenagers from authoritarian, authoritative, indulgent and neglectful homes. Family Therapy, 35(1), 43-59. https://doi.org/10.2466/pr0.100.3.731-745

Maslow, A. (1987). Motivation \& personality (3 ed.). New York : Harber \& Row Publishers.

Mekonnen, M. (2017). Effects of family educational background, dwelling and parenting style on students' academic acheivement. Academic Journals- Academic Research and Reviews, 12(18), 939-949.

Murphy, V. (2014). Second language learning in early years: trends \& contexts. International Journal of Applied Linguistics, 25(2), 268-272. https://doi.org/10.1111/ijal.12116

Nguyen, V. (2008). Perceptions of Vietnamese fathers' acculturation levels, parenting styles and mental health outcomes in Vietnamese American adolescents immigrants. PubMed, 53(4), 337-346. https://doi.org/10.1093/sw/53.4.337 
Olivari, M., Wahn, E., Kassotaki , K., \& Antonopoulou, K. (2015). Adolescents perceptions of parenting styles in Sweden, Italy and Greece: An exploratory study. Europe's Journal of Psychology, 244-258. https://doi.org/10.5964/ejop.v11i2.887

Osenweugwor, A. (2014). Perceived parenting styles as correlates of self- esteem among adolescents in secondary schools. The British Journal of Social Work, 53(4), 337-346.

Pinquart, M \& Gerke, D-C. (2019). Associations of parenting styles with self-esteem in children and adolescents: A meta-analysis. Journal of Child \&Family Studies, 43-44. https://doi.org/10.1007/s10826-019-01417-5

Raymore, L., Godbey, G., \& Crawford, D. (1994). Self-esteem, gender, and socioeconomic status: Their relation to perceptions of constraint on leisure among adolescents. Journal of Leisure Research, 99-118. https://doi.org/10.1080/00222216.1994.11969948

Reasoner, R. (2005). The true meaning of self-esteem. The International Council for SelfEsteem.

Rifai, S. E. (2008). The relationship between self esteem, gender, grade level and academic achievement in secondary schools' classes in Lebanon. Thesis, 90-95.

Robins, R., Orth , V., \& Trzesniewski, K. (2010). Self -esteem development from young adulthood to old age. Journal of Personality and Social Psychology, 98(4), 645-658.

Robinson, C., Mandleco, B., Olsen, S. F., \& Hart, C. H. (2001). The parenting styles and dimensions questionnaire. Handbook of family measurement techniques, 3, 319-321.

Rosenberg, M., \& Simmons, G. (1973). Black \& White Self Esteem: the Urban School Child. Michigan: MPublishing, University of Michigan Library.

Rosenberg, M. (1965). Society and the Adolescent Self Image. Princeton, New Jersey: Princeton University Press.

Rosenberg, M., \& Pearlin, L. (1978). Social class and self-esteem among children and adults . American Journal of Sociology, 53-77. https://doi.org/10.1086/226740

Ross, J., Fertman, C., \& Chubb, N. (1997). Adolescent self esteem \&locus of control: a longitudinal study of gender \& age differences. Journal of Adolescence, 32(25), 113129.

Rudy, D., \& Grusec, J. (2006). Authoritarian parenting in individualist and collectivist groups: associations with maternal emotion and cognition and children's self-esteem. Journal of Family Psychology, 68-78. https://doi.org/10.1037/0893-3200.20.1.68

Sahin, E., Barut, Y., \& Ersanli, E. (2013). Parental educational Level positively affects self esteem of Turkish adolescents. Journal of Education \& Practice.

Steinberg, L. (2002). Adolescence (6 ed.). McGraw-Hill.

Steinberg, L., Dornbusch, S., \& Brown , B. (1992). Ethnic differences in adolescents achievement: an ecological perspective. American Psychologist, 47, 723-729. https:// doi.org/10.1037/0003-066X.47.6.723

Tkacova, S (2017). The effects of age, sex and parenting styles on self-esteem in young adult. New York: State University of New York.

Vega, W. (1990). Hispanic families in the 1980s: a decade of research. Journal of Marriage and the Family, 52(4), 1015-1024. https://doi/10.1037/0003-066X.47.6.723

Weiten, W., Dunn, D., \& Hammer, E. (2014). Psychology Applied to Modern life: Adjustment in the 21 Century (11 ed.). Florence : Cengage Learning.

Yamawak, N., Nelson, J., \& Omoni, M. (2010). Self-esteem \& life saitsfaction as mediators between parental bonding \& psychosocial well being in Japanese young adults. International Journal of Psychology and Counseling, 3(1), 1-8.

Ying, Y., Tsai, I., \& Lee, P. (2001). Cultural predictors of self-esteem: A study of Chinese American female and male young adults. Cultural Diversity and Ethnic Minority Psychology, 7(3), 284-297. https://doi.org/10.1037//1099-9809.7.3.284 